\title{
Biomassa de espécies florestais para produção de carvão vegetal
}

\author{
Forest species biomass for the production of charcoal
}

\author{
Amanda Pinheiro FortalezaI, José Jaime Pessoa do Nascimento Filho"I, Rafaela \\ Patrícia da Silva Ceretta ${ }^{\mathrm{II}}$, Denes de Souza Barros ${ }^{\mathrm{IV}}$, Simonne Sampaio da Silva ${ }^{\mathrm{V}}$
}

\section{Resumo}

Devido à alta demanda das empresas por geração de energia oriunda de fontes renováveis, o objetivo deste estudo foi analisar as propriedades da madeira e do carvão proveniente de três espécies florestais: Ceiba pentandra (L.) Gaertn. (Sumaúma), Guatteria sp. (Envirão) e Brosimum sp. (Mumuré). O material foi coletado na Empresa Rosa Madeireira Ltda. De cada espécie foram coletadas 10 amostras para a análise das propriedades da madeira e do carvão e, destas, 5 amostras foram utilizadas para a análise química. As propriedades avaliadas foram: densidade básica e teor de umidade da madeira, rendimento gravimétrico, densidade aparente e teor de umidade do carvão e, composição química. Os dados foram submetidos à Análise de Variância e médias comparadas pelo teste Tukey a $5 \%$ de probabilidade, assim como os efeitos da densidade básica sobre o rendimento gravimétrico e sobre a densidade aparente foram testados pela correlação de Pearson. As análises indicaram que o fator espécies apresentou efeito significativo em todos os parâmetros, exceto quanto ao teor de umidade do carvão. Sobre densidade básica da madeira, a Sumaúma apresentou o menor valor médio $\left(0,4302 \pm 0,0157 \mathrm{~g} / \mathrm{cm}^{3}\right)$ e Mumuré, o maior $\left(0,5276 \pm 0,0251 \mathrm{~g} / \mathrm{cm}^{3}\right)$. Entretanto, com relação ao teor de umidade, Sumaúma foi a espécie que apresentou o maior teor $(47,46 \% \pm 2,88)$. Os valores de rendimento em carvão variaram entre 30,03\% \$1,95 (Envirão) e 32,35\% \pm 1,46 (Sumaúma). Houve correlação entre a densidade da madeira e o rendimento gravimétrico para a espécie Mumuré $(\mathrm{P}=-0,553)$, no entanto, considerada negativa. Entretanto, correlação positiva foi encontrada para Sumaúma $(P=0,058)$ e Envirão $(P=0,955)$. Nos testes de densidade do carvão, o Mumuré apresentou o maior valor médio $\left(0,3173 \pm 0,0116 \mathrm{~g} / \mathrm{cm}^{3}\right)$ e Envirão o menor $\left(0,2654 \pm 0,0407 \mathrm{~g} / \mathrm{cm}^{3}\right)$. Uma relação direta e positiva entre a densidade básica da madeira e a densidade relativa aparente do carvão foi encontrada. Tratando-se da composição química, o fator espécies não apresentou efeito significativo.

Palavras-chave: Resíduos florestais; Propriedades da madeira; Propriedades do carvão

\begin{abstract}
Due to the high demand of companies for generating energy from renewable sources, the aim of this study was to analyze the proprieties of wood and charcoal from three forest species: Ceiba pentandra (L.) Gaertn. (Sumaúma), Guatteria sp. (Envirão) e Brosimum sp. (Mumuré). The material was collected at the Empresa Rosa Madeireira Ltda., and from each species, 10 samples were collected for physical proprieties analysis of wood and charcoal, for this one, 5 samples were utilized for chemical analysis. The proprieties evaluated were: basic density and moisture content of wood, gravimetric charcoal yield, the apparent density and moisture content of charcoal and chemical composition. The data was submitted to the Analysis of Variance and the means were compared by the Tukey test at $5 \%$ probability level, as well as the effects of the basic density on the gravimetric yield and on the apparent density were tested using Pearson's Correlation. The analysis indicated that the species factor had a significant effect on all the parameters, except for the moisture content of charcoal. Regarding the wood basic density, Sumaúma showed the lowest mean value $\left(0.4302 \pm 0.0157 \mathrm{~g} / \mathrm{cm}^{3}\right)$ and Mumuré, the highest $\left(0.5276 \pm 0.0251 \mathrm{~g} / \mathrm{cm}^{3}\right)$. However, in relation to the moisture content, Sumaúma was the species that presented the highest content $(47.46 \% \pm 2.88)$. The charcoal yield values ranged from $30.03 \% \pm 1.95$ (Envirão) to $32.35 \% \pm 1.46$ (Sumaúma). There was a correlation between the wood density and gravimetric yield for the Mumuré species ( $\mathrm{p}=0.553$ ), but it was considered negative. Nevertheless, a positive correlation was found for Sumaúma ( $\mathrm{p}=0.058)$ and Envirão $(\mathrm{p}=0.955)$. In the charcoal density tests, Mumuré showed the highest mean value

\footnotetext{
Engenheira Florestal, Mestranda em Ciências Florestais, Universidade Federal Rural da Amazônia, Av. Pres. Tancredo Neves, 2501, Bairro Montese, CEP 66077-901, Belém (PA), Brasil. amanda.fortaleza1@hotmail.com (ORCID: 0000-0002-8933-2698)

Engenheiro Florestal, Secretaria Municipal de Meio Ambiente, Av. Barão de Capanema, 1194, Bairro Centro, CEP 68700-005, Capanema (PA), Brasil. jaime-linux@hotmail.com (ORCID: 0000-0002-0798-3076) CEP 66077-901, Belém (PA), Brasil. rafaelapatricia_@hotmail.com (ORCID: 0000-0003-4181-5364) denesbarros@yahoo.com.br (ORCID: 0000-0001-5317-3923)

Engenheira Florestal, MSc., Doutora em Ciência e Tecnologia da Madeira, Professora da Universidade Federal Rural da Amazônia, Rodovia PA 256, Km 6, CEP 68627-451, Paragominas (PA), Brasil. simonne.sampaio@ufra.edu.br (ORCID: 0000-0002-8538-1193)
}

III Engenheira Florestal, Mestranda em Ciências Florestais, Universidade Federal Rural da Amazônia, Av. Pres. Tancredo Neves, 2501, Bairro Montese,

IV Engenheiro Florestal, MSc., Professor da Universidade Federal Rural da Amazônia, Rod. PA 256, Km 6, CEP 68627-451, Paragominas (PA), Brasil.
\end{abstract}


$\left(0.3173 \pm 0.0116 \mathrm{~g} / \mathrm{cm}^{3}\right)$ and Envirão, the lowest $\left(0.2654 \pm 0.0407 \mathrm{~g} / \mathrm{cm}^{3}\right)$. A direct and positive relationship between the basic density of wood and relative apparent density of charcoal was found. For the chemical composition, the species factor did not show a significant effect.

Keywords: Forest residues; Wood proprieties; Proprieties of charcoal

\section{Introdução}

A cobertura florestal do território brasileiro associada às condições edafoclimáticas favoráveis para a silvicultura, confere ao país grandes vantagens para a atividade florestal quando se compara ao restante do mundo. Como consequência, a participação no contexto da geração de energia oriunda de fontes renováveis se destaca com a mesma magnitude. O uso da madeira no Brasil, visando à geração de energia, tem sido historicamente relacionado à produção de carvão vegetal, e essa, se destaca em decorrência da demanda existente pelo produto junto ao setor siderúrgico (SANTOS et al., 2011).

O Brasil é o maior produtor mundial de carvão vegetal. Em 2010, foram produzidos 11,6 milhões de metros cúbicos de carvão vegetal a partir de florestas plantadas, dos quais $66,2 \%$ foram consumidos pelos setores de ferro-gusa, aço e ferro-liga, sendo o único país no mundo no qual o carvão vegetal tem uma aplicação industrial em grande escala, como destino principal, a produção de ferro-gusa e aço e ainda ferro-liga e silício metálico. É nesse contexto que o carvão vegetal se tornou um dos combustíveis e redutores mais importantes na indústria siderúrgica, pois é renovável, e além de ter baixo teor de cinzas, é praticamente isento de enxofre e fósforo, tendo sua tecnologia para fabricação já amplamente consolidada no Brasil (ASSOCIAÇÃO BRASILEIRA DE PRODUTORES DE FLORESTAS PLANTADAS, 2011).

Mesmo que o consumo de carvão vegetal tenha atingido seu ponto máximo em 2005, quando foram produzidos e consumidos mais de 38 milhões de metros cúbicos, as plantações florestais homogêneas ainda não são capazes de suprir toda a demanda das empresas, de forma que, por ano, há um deficit anual médio de quase 50\% (o que equivale no mínimo a 100 mil hectares plantados) que é suprido com o abastecimento de madeira e resíduos advindos do manejo de florestas naturais (ASSOCIAÇÃO MINEIRA DE SILVICULTURA, 2009).

Como esta alta demanda das empresas por fontes de energia ainda não foi suprida exclusivamente por florestas energéticas, uma parte dos resíduos de madeira gerados na indústria madeireira tem sido destinada à produção de produtos de maior valor agregado como carvão, cabos, briquete, embalagem, etc. Contudo, estes usos foram identificados com maior frequência nos levantamentos realizados nas regiões Centro-Oeste, Sudeste e Sul do país, em que também se aproveitam os resíduos de madeira para queima em caldeiras e fornos artesanais (olarias) (WIECHETECK, 2009).

A obrigatoriedade da autossuficiência dentro do contexto das empresas demandantes dessa matéria-prima notadamente no Estado do Pará, definida no Termo de Compromisso e Ajuste de Conduta do Ministério Público Federal (BRASIL, 2012) tem dado uma maior importância ao desenvolvimento de novas tecnologias que envolvem os processos para a produção de madeira, avaliação da sua qualidade, bem como sua transformação em carvão vegetal (TRUGILHO et al., 2005).

Um dos principais aspectos relacionados ao aproveitamento de resíduos de madeira voltado à geração de energia é sua viabilidade econômico-financeira. Alguns levantamentos de campo apontaram um deficit de informação referente à possibilidade de gerar energia elétrica a partir da queima dos resíduos de madeira por parte de muitos madeireiros, notadamente na região Norte do país. No entanto, o conhecimento do volume gerado, da qualidade e especificação dos resíduos e das possibilidades de uso deste material podem gerar uma alternativa viável de sua utilização (WIECHETECK, 2009).

Há, portanto, a necessidade de se buscar conhecimentos sobre a carbonização de resíduos de espécies nativas da região amazônica como fonte energética, permitindo assim a caracterização das propriedades do carvão vegetal, que por sua vez é oriundo de resíduos de exploração florestal 
e de indústrias madeireiras (SILVA et al., 2007). Dentro deste contexto, o objetivo do trabalho foi analisar as propriedades da madeira e do carvão vegetal proveniente de resíduos de serraria de três espécies florestais: Ceiba pentandra (L.) Gaertn. (Sumaúma), Guatteria sp. (Envirão) e Brosimum sp. (Mumuré), comercializadas no município de Paragominas, no Estado do Pará.

\section{Material e método}

O material estudado foi coletado na Empresa Rosa Madeireira Ltda., situada no município de Paragominas - PA. A empresa tem visado ao comércio atacadista de madeira e produtos derivados, mas dentro deste contexto, os resíduos analisados são potenciais candidatos para o uso energético. O município está localizado entre as coordenadas de $2^{\circ} 25^{\prime}$ e $4^{\circ} 09^{\prime} \mathrm{S}$ e $46^{\circ} 25^{\prime}$ e $48^{\circ} 54^{\prime}$ W Gr, com o clima do tipo “Aw”, apresentando médias anuais de temperatura e precipitação pluviométrica de $26,3^{\circ} \mathrm{C}$ e $1.800 \mathrm{~mm} / \mathrm{ano}$, respectivamente, e umidade relativa em torno de 85\% (CITY BRASIL, 2016).

Para este estudo foram selecionadas as espécies Ceiba pentandra (L.) Gaertn. (Sumaúma), Guatteria sp. (Envirão) e Brosimum sp. (Mumuré), tomando-se como base a maior disponibilidade de resíduos na empresa no período em que se desenvolveu o trabalho, além de serem espécies florestais exploradas no município. Vale ressaltar ainda que a identificação do material coletado foi até gênero para as espécies conhecidas como Envirão e Mumuré, portanto, a análise pode ser considerada genérica e não específica para cada espécie avaliada.

Para avaliação das propriedades físicas e químicas, do lote de resíduos de cada espécie selecionada foram coletadas 10 amostras de madeira, perfazendo um total de 30 amostras (corpos de prova), com dimensões nominais de $2,0 \mathrm{~cm} \times 3,0 \mathrm{~cm}$ e comprimento, ao longo das fibras, de 5,0 cm, como recomenda a ABNT NBR 7190 (1997) as quais foram enviadas ao Laboratório Multidisciplinar da Universidade Federal Rural da Amazônia (UFRA), em Paragominas.

\section{Propriedades físicas da madeira, do carvão e análise química imediata}

Foram preparados 10 corpos de provas para cada espécie. A massa seca das amostras foi determinada com o auxílio de uma balança analítica de precisão e os volumes determinados através do método de pesagem baseado no princípio de Arquimedes. A partir dos dados coletados, a densidade básica foi determinada. O mesmo foi considerado para cálculo da densidade aparente do carvão, como descreve a Tabela 1.

Tratando-se do teor de umidade da madeira, após a determinação do volume saturado dos corpos de prova, estes foram submetidos à secagem em uma estufa a $103 \pm 2^{\circ} \mathrm{C}$ até atingir a estabilização do peso após três pesagens consecutivas, condição em que caracteriza a ausência completa de água na parede celular ( $0 \%$ de umidade).

As carbonizações foram realizadas em um forno elétrico tipo mufla. O controle do aquecimento foi manual, com uma taxa média de $1,67^{\circ} \mathrm{C}$ por minuto. A temperatura inicial foi sempre a ambiente e a máxima foi de $500^{\circ} \mathrm{C}$, permanecendo estabilizada por um período de 30 minutos. O tempo de carbonização foi, portanto, de 5 horas e 30 minutos e o material carbonizado previamente seco em estufa de circulação de ar a $103 \pm 2{ }^{\circ} \mathrm{C}$.

A análise do Rendimento gravimétrico foi realizada conforme demonstra a Tabela 1. Após a determinação do teor de umidade do carvão, as amostras foram moídas até a granulometria desejada $(0,210$ a $0,150 \mathrm{~mm})$. O carvão moído foi então classificado em peneiras de $1,5 \mathrm{~mm}$ e 2 $\mathrm{mm}$. Posteriormente, esse material foi utilizado na análise química imediata do carvão vegetal para a determinação dos teores de cinzas $(\mathrm{CZ})$, de materiais voláteis $(\mathrm{MV})$ e de carbono fixo $(\mathrm{CF})$ contidos no carvão, para cada espécie estudada.

Para a análise do teor de cinzas, foram utilizados cinco cadinhos sem tampas para cada amostra de carvão, totalizando cinco amostras por espécie. Em seguida, os cadinhos foram 
submetidos à combustão completa sob temperatura de $700^{\circ} \mathrm{C}$ durante 5 horas. Ao final, o material residual foi pesado, utilizando-se uma balança analítica de precisão $0,0001 \mathrm{~g}$. O teor de cinzas foi determinado conforme equação (Tabela 1).

Para a análise do teor de materiais voláteis foram utilizados cinco cadinhos com tampas para cada amostra de carvão, totalizando cinco amostras para cada espécie. Estes cadinhos foram pesados em uma balança analítica a seguir, pesou-se 1 grama de carvão moído em cada cadinho. Posteriormente, os cadinhos com as amostras foram submetidos à calcinação em um forno mufla a $900^{\circ} \mathrm{C}$, durante 7 minutos. O material residual foi então pesado em balança analítica de precisão 0,0001g. Ao final, o teor de materiais voláteis foi determinado conforme equação (Tabela 1). A partir da obtenção do teor de cinzas e do teor de materiais voláteis, o teor de carbono fixo foi determinado indiretamente conforme apresenta a Tabela 1.

Tabela 1 - Equações utilizadas na obtenção dos resultados do presente estudo.

Table 1 - Equations used to obtain the results of the present study.

\begin{tabular}{|c|c|c|}
\hline Propriedades Físicas da Madeira e do Carvão & Fonte & Equação \\
\hline $\begin{array}{l}\text { Densidade básica da madeira } \\
\text { Densidade relativa aparente do carvão }\end{array}$ & ABNT NBR 7190 (1997) & $\rho_{(\text {bas })}=\frac{m_{s}}{V_{(\text {sat })}}$ \\
\hline Teor de umidade & ABNT NBR 7190 (1997) & $\mathrm{U}(\%)=\frac{\mathrm{m}_{\mathrm{i}}-\mathrm{m}_{\mathrm{s}}}{\mathrm{m}_{\mathrm{s}}} \times 100$ \\
\hline Rendimento gravimétrico & SILVA et al. (2007) & $\mathrm{RGc}=\frac{\mathrm{P}_{\text {carvão }}}{\mathrm{P}_{\text {madeira }}} \times 100$ \\
\hline Composição Química Imediata & Fonte & Equação \\
\hline Teor de cinzas & ABNT NBR 8112 (1986) & $\mathrm{Z}=\frac{\mathrm{m}_{1}-\mathrm{m}_{0}}{\mathrm{~m}} \times 100$ \\
\hline Teor de materiais voláteis & ABNT NBR 8112 (1986) & $\mathrm{MV}=\frac{\mathrm{m}_{2}-\mathrm{m}_{3}}{\mathrm{~m}} \times 100$ \\
\hline Teor de carbono fixo & ABNT NBR 8112 (1986) & $\mathrm{CF}=100-(\mathrm{CZ}+\mathrm{MV})$ \\
\hline
\end{tabular}

\section{Delineamento experimental e análise estatística}

Para a avaliação dos resultados das análises físicas da madeira e do carvão foi empregado um delineamento inteiramente casualizado, com três tratamentos (espécies) e 10 repetições por espécie. Quanto às análises químicas do carvão, empregou-se o mesmo delineamento, com três tratamentos (espécies) e 5 repetições por espécie. Inicialmente foi testada a aderência dos dados à distribuição normal, utilizando-se o Teste Shapiro-Wilk à nível de $5 \%$ de significância. Obtevese a normalidade para todas as variáveis de resposta dos tratamentos avaliados. Em seguida, os resultados obtidos foram submetidos à Análise de Variância (ANOVA) e médias comparadas pelo teste Tukey a $5 \%$ de probabilidade, com auxílio do programa Statistical Package for Social Science (SPSS) versão 20.0.

O efeito da densidade básica da madeira sobre o rendimento gravimétrico do carvão, assim como sobre a densidade aparente do carvão foi testado por meio do coeficiente de correlação de Pearson (P), para cada espécie estudada. 


\section{Resultados e discussão}

Os resultados obtidos para a análise de variância das propriedades físicas da madeira e do carvão são apresentados na Tabela 2. As análises estatísticas indicaram que o fator tratamento, neste caso as espécies, apresentou efeito significativo em todos os parâmetros avaliados, com exceção do teor de umidade do carvão.

Tabela 2 - Valores do teste F da Análise de Variância dos dados coletados das madeiras provenientes de resíduos de serraria de três espécies florestais, exploradas no município de Paragominas, Pará.

Table 2 - Values of $\mathrm{F}$ test of the Variance Analysis of the data collection of wood originated from sawmill residues of three forest species, exploited in the municipality of Paragominas, Pará state.

\begin{tabular}{lcccccc}
\hline $\begin{array}{l}\text { Causa de } \\
\text { Variação }\end{array}$ & GL & $\begin{array}{c}\text { Densidade da } \\
\text { madeira }\end{array}$ & $\begin{array}{c}\text { Umidade da } \\
\text { madeira }\end{array}$ & $\begin{array}{c}\text { Rendimento } \\
\text { gravimétrico }\end{array}$ & $\begin{array}{c}\text { Densidade } \\
\text { aparente }\end{array}$ & $\begin{array}{c}\text { Umidade do } \\
\text { carvão }\end{array}$ \\
\hline Espécies & 2 & $19,92^{* *}$ & $15,51^{* *}$ & $6,35^{* *}$ & $11,02^{* *}$ & 3,45 \\
Resíduos & 27 & - & - & - & - & - \\
Total & 29 & - & - & - & - & - \\
\hline
\end{tabular}

Em que: $G L=$ Grau de liberdade. ${ }^{* *}$ Diferença significativa à $1 \%$ de probabilidade.

\section{Densidade básica e Teor de umidade da madeira}

Nos testes de densidade básica da madeira observou-se que a Sumaúma apresentou densidade média de 0,4302 $\pm 0,0157 \mathrm{~g} \mathrm{~cm}^{-3}$, Envirão de $0,4637 \pm 0,0531 \mathrm{~g} / \mathrm{cm}^{3}$ e Mumuré de 0,5276 \pm $0,0251 \mathrm{~g} / \mathrm{cm}^{3}$ (Tabela 3). Em média, o maior valor de densidade da madeira corresponde à espécie Mumuré, diferindo estatisticamente das demais espécies. Sumaúma e Envirão não apresentaram diferença significativa entre si.

Tabela 3 - Estatística descritiva da densidade básica e teor de umidade das madeiras provenientes de resíduos de serraria de três espécies florestais, exploradas no município de Paragominas, Pará.

Table 3 - Descriptive statistics of the basic density and moisture content of wood originated from sawmill residues of three forest species, exploited in the municipality of Paragominas,

Pará state.

\begin{tabular}{lcccc}
\hline Tratamento & $\begin{array}{c}\text { Densidade básica }\left(\mathbf{g} / \mathbf{c m}^{\mathbf{3}}\right) \\
\text { Média } \pm \text { Desvio padrão }\end{array}$ & $\begin{array}{c}\text { Coeficiente de } \\
\text { Variação }(\mathbf{C V}) \%\end{array}$ & $\begin{array}{c}\text { Teor de umidade } \\
(\%) \text { Média } \pm \text { Desvio } \\
\text { padrão }\end{array}$ & $\begin{array}{c}\text { Coeficiente de } \\
\text { Variação }(\mathbf{C V}) \text { \% }\end{array}$ \\
\hline $\begin{array}{l}\text { Ceiba pentandra } \\
\text { (L.) Gaertn. }\end{array}$ & $0,4302 \pm 0,0157 \mathrm{~b}$ & 3,65 & $47,46 \pm 2,88 \mathrm{a}$ & 6,06 \\
$\begin{array}{l}\text { Guatteria sp. } \\
\begin{array}{l}\text { Brosimum sp. } \\
\hline\end{array}\end{array}$ & $0,4637 \pm 0,0531 \mathrm{~b}$ & 11,45 & $41,33 \pm 6,81 \mathrm{~b}$ & 16,47 \\
\hline
\end{tabular}

Letras diferentes referem-se a tratamentos estatisticamente diferentes entre si, segundo o teste de Tukey a $95 \%$ de confiabilidade. 
Tendo como base a literatura, as madeiras são classificadas em madeira de baixa densidade (abaixo de $0,5 \mathrm{~g} / \mathrm{cm}^{3}$ ), densidade média ou moderadamente duras (entre $0,5 \mathrm{~g} / \mathrm{cm}^{3}$ e $0,7 \mathrm{~g} / \mathrm{cm}^{3}$ ) e densidade básica pesada ou duras (acima de 0,7 g/ $\mathrm{cm}^{3}$ ) (VALE; SARMENTO; ALMEIDA, 2005). Nesse sentido, Mumuré foi classificada como madeira de densidade média ou moderadamente dura e as demais espécies, consideradas de baixa densidade.

Chudnoff (1980) e Loureiro et al. (2000) encontraram para Sumaúma densidade média entre 0,30 e 0,37 g cm-3, respectivamente, enquanto que Araújo (2007) encontrou 0,29 g cm-3. Para o Envirão, o valor encontrado por Araújo (2007) foi de $0,57 \mathrm{~g} \mathrm{~cm}-3$ e para Mumuré, o valor apresentado por Nogueira et al. (2007) foi de 0,51 g cm-3. Dessa forma, pode-se verificar que a madeira é um material heterogêneo quando se trata de suas propriedades, por apresentar diferenças significativas até mesmo em indivíduos de mesma espécie (GONÇALEZ et al., 2014). Vale destacar que para estas duas últimas espécies estudadas, a identificação botânica não chegou em nível de espécie, mas de gênero. Logo, este fato pode ser uma das causas para a distinção de valores. Ainda sobre isto, é importante destacar que mesmo sendo uma análise considerando-se o gênero, o coeficiente de variação foi baixo para a densidade básica.

Estas diferenças entre os valores encontrados para a densidade básica refletem a grande variabilidade entre as espécies ou até mesmo entre indivíduos de mesma espécie, como resultado de sua constituição anatômica e química (ASSIS et al., 2012). Além disso, essa variação entre densidades de espécies pode ser uma consequência da diferença de sítios, principalmente, quando se considera a diferença na fertilidade dos solos. Assim, pode-se dizer que o ambiente é um dos fatores que influenciam a variabilidade da madeira, seja física e/ou química.

Na produção de carvão vegetal, a densidade da madeira deve ser analisada sob vários aspectos, podendo várias considerações serem feitas em torno da mesma. A densidade é uma propriedade que afeta a capacidade de produção de carvoaria, porque, para um determinado volume de forno, a utilização de madeira mais densa resulta em maior produção em peso. Além disto, madeira mais densa produz carvão com densidade mais elevada, com vantagens para alguns de seus usos (BRITO, 1993).

As espécies apresentaram valores de teores de umidade médios que variaram entre 33,93 $\pm 5,84$ a 47,46\% $\pm 2,88$ (Tabela 3). Em média, o maior valor para o teor de umidade da madeira foi encontrado para a espécie Sumaúma, diferindo estatisticamente das demais espécies Envirão e Mumuré, as quais também diferiram entre si.

Os valores médios para o teor de umidade encontrados neste trabalho estão dentro do limite recomendado, obedecendo o teor de umidade máximo que uma madeira pode ser queimada no forno que está em torno de 65\% a 70\% em base úmida, de acordo com Jara (1989). Segundo Lima, Abdala e Wenzel (2008), a partir de 60\% de umidade, a combustão ocorre, no entanto, a quantidade de energia útil será muito baixa devido à elevada quantidade de água presente. No entanto, de acordo com Brand (2010), o teor de umidade da biomassa para queima direta deve estar próximo a $25 \%$ na base úmida. Logo, é importante ressaltar que não há consenso na literatura especializada quanto a estes valores.

O teor de umidade da madeira mais adequado para a carbonização deve ser inferior a 20 ou $30 \%$ (base seca), o que de acordo com Brand (2010), corresponde a um teor de umidade próximo a 25\% (base úmida). Alguns autores afirmam que tora estocada ao lado do forno (sem cobertura) pode apresentar alto teor de umidade, o que faz com que a taxa de aquecimento seja muito lenta e que a temperatura máxima média não seja constante, devido ao excesso de vapor de água liberado pela madeira, e consequentemente, aumento no tempo de ignição e de carbonização (ARRUDA et al., 2011). Assim, esse fator pode ter sido uma das causas das madeiras das espécies estudadas apresentarem valores médios dos teores de umidade superiores a $30 \%$.

Devido à umidade, é inevitável que ocorra perda de calor decorrente da presença de água na madeira, pois sua evaporação absorve energia térmica (JARA, 1989). Logo, a umidade da madeira afeta significativamente o rendimento em carvão, causando uma diminuição do mesmo com o aumento do seu teor de umidade.

A madeira de Sumaúma apresentou o maior valor médio (47,46\%). Vale ressaltar que a madeira da espécie que apresentou o menor valor médio para o teor de umidade $(33,93 \%)$ foi a mesma que 
apresentou o maior valor médio de densidade, o Mumuré (Figura 1), o que está de acordo com Foelkel, Brasil e Barrichelo (1971), os quais afirmaram que a densidade da madeira e o teor de umidade são inversamente proporcionais. Segundo os autores, o teor de umidade e a densidade da madeira são inversamente proporcionais, pois quanto maior o volume de água, menor a quantidade dos demais elementos químicos presentes na madeira, tais como a celulose, a hemicelulose e a lignina.

Figura 1 - Valores médios da densidade básica e teor de umidade da madeira proveniente de resíduos de serraria de três espécies florestais, exploradas no município de Paragominas, Pará.

Figure 1 - Mean values of basic density and moisture content of wood coming from sawmill residues of three forest species exploited, in the municipality of Paragominas, Pará state.

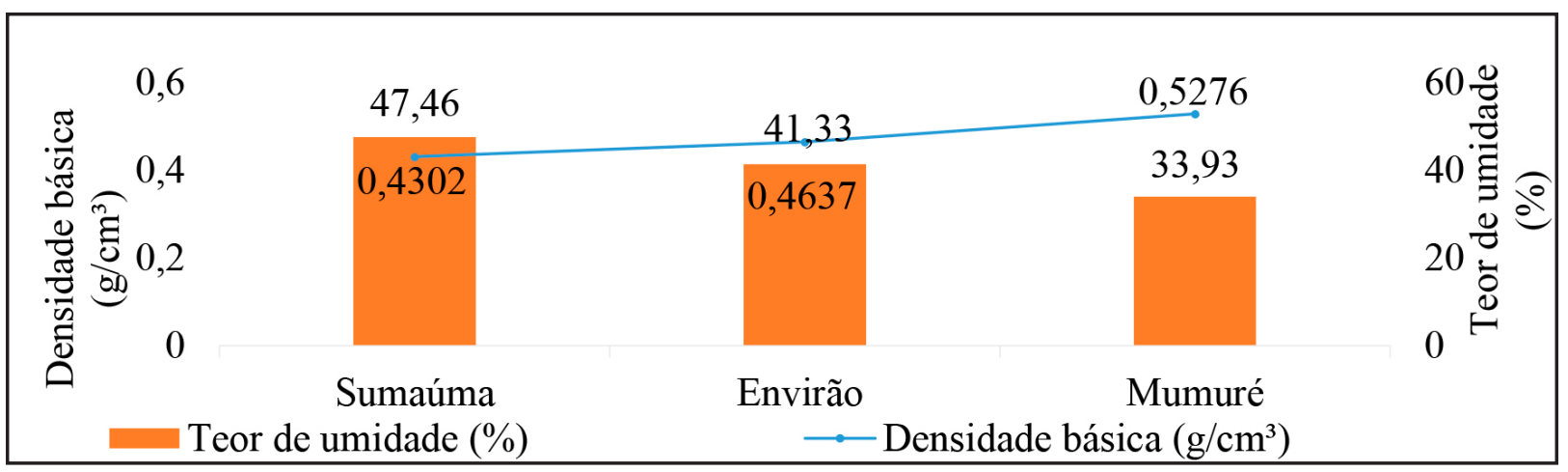

Fonte: Autores (2019)

\section{Rendimento gravimétrico do carvão}

Os valores de rendimento em carvão das espécies estudadas variaram entre $30,03 \% \pm$ 1,95 (Envirão) e 32,35\% $\pm 1,46$ (Sumaúma). O maior valor médio para o rendimento gravimétrico corresponde à espécie Sumaúma e menor valor médio ao Envirão. Pela comparação de médias pelo Teste de Tukey, Sumaúma e Envirão foram diferentes estatisticamente entre si, com exceção da Sumaúma e Mumuré e; Envirão e Mumuré que não apresentaram diferença significativa entre si (Tabela 4).

Tabela 4 - Estatística descritiva do rendimento gravimétrico médio de resíduos de serraria de três espécies florestais, exploradas no município de Paragominas, Pará.

Table 4 - Descriptive statistics of mean gravimetric yield from sawmill residues of three forest species exploited, in the municipality of Paragominas, Pará state.

\begin{tabular}{lcc}
\hline \multicolumn{1}{c}{ Tratamento } & $\begin{array}{c}\text { Rendimento gravimétrico (\%) Média } \pm \text { Desvio } \\
\text { padrão }\end{array}$ & $\begin{array}{c}\text { Coeficiente de } \\
\text { Variação }(\mathbf{C V}) \%\end{array}$ \\
\hline $\begin{array}{l}\text { Ceiba pentandra }(\mathbf{L} .) \\
\text { Gaertn. }\end{array}$ & $32,35 \pm 1,46 \mathrm{a}$ & 4,53 \\
Guatteria sp. & $30,03 \pm 1,95 \mathrm{~b}$ & 6,50 \\
Brosimum sp. & $31,30 \pm 0,64 \mathrm{ab}$ & 2,06 \\
\hline
\end{tabular}

Letras diferentes referem-se a tratamentos estatisticamente diferentes entre si, segundo o teste de Tukey a $95 \%$ de confiabilidade. 
O rendimento gravimétrico das espécies estudadas foi superior aos valores encontrados por Vale, Dias e Santana (2010) para cinco espécies de ocorrência no Cerrado, os quais variaram de 25 a $28 \%$ e inferior aos valores encontrados por Vale e Nogueira (2001), ao estudarem 12 espécies de ocorrência no Bioma Cerrado, cujos resultados variaram de 32 a $39 \%$ e aos valores encontrados por Medeiros Neto et al. (2012), aos estudarem as espécies Poincianella pyramidalis e Handroanthus impetiginosus que encontraram valores que variaram entre 37 e $44 \%$. Para Oliveira et al. (2010), os diferentes sistemas de carbonização e as características da madeira utilizada como matéria-prima determinarão o rendimento do processo de transformação da madeira e influenciarão as características do carvão vegetal.

De acordo com a Figura 2, houve correlação entre a densidade básica da madeira e o rendimento em carvão vegetal para a espécie Mumuré (correlação de Pearson $=-0,553$ ), no entanto, considerada negativa. Em contrapartida, uma correlação positiva entre essas variáveis foi encontrada para as espécies Sumaúma (correlação de Pearson $=0,058$ ), sendo classificada como fraca de acordo com Martins (2014) e para o Envirão (correlação de Pearson $=0,955$ ), sendo classificada como forte, de acordo com Dancey e Reidy (2006). Estes resultados indicam que amostras de maior massa específica produzem maior rendimento em carvão. O mesmo foi encontrado para Pastore, Okino e Pastores Junior (1989), ao estudarem 20 espécies nativas da Amazônia, encontrando correlação direta entre essas variáveis.

Figura 2 - Correlação entre a densidade básica da madeira e rendimento gravimétrico do carvão de resíduos de serraria de Mumuré (Brosimum sp.), Sumaúma (Ceiba pentandra (L.) Gaertn.) e Envirão (Guatteria sp.), exploradas no município de Paragominas, Pará.

Figure 2 - Correlation between the basic density of wood and gravimetric yield from sawmill residues of Mumuré (Brosimum sp.), Sumaúma (Ceiba pentandra (L.) Gaertn.) and Envirão

(Guatteria sp.), exploited in the municipality of Paragominas, Pará state.

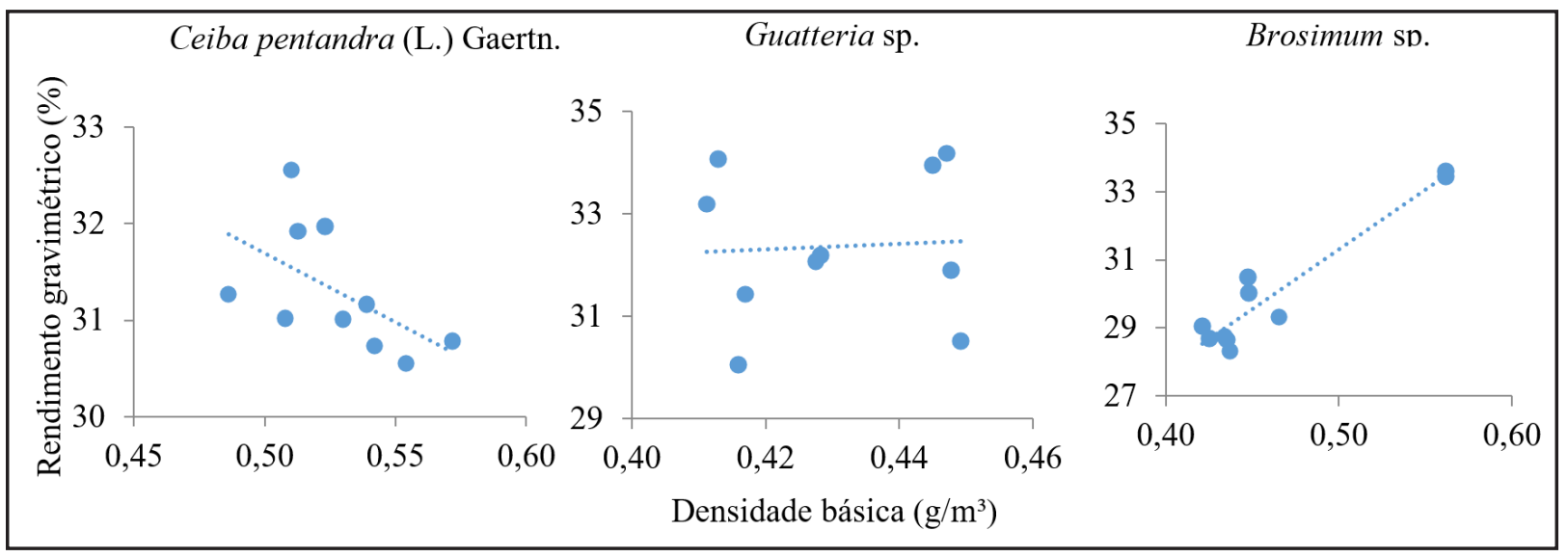

Fonte: Autores (2019)

Entretanto, uma correlação positiva entre essas variáveis foi encontrada para as espécies Sumaúma (correlação de Pearson $=0,058$ ) (Figura 2), sendo classificada como fraca de acordo com Martins (2014). E para Envirão (correlação de Pearson = 0,955) (Figura 2), sendo classificada como forte, de acordo com Dancey e Reidy (2006). Estes resultados indicam que amostras de maior massa específica produzem maior rendimento em carvão. Assim como foram encontrados também por Pastore, Okino e Pastore Junior (1989), ao estudarem 20 es pécies nativas da Amazônia, encontrando correlação direta entre essas variáveis. 
Segundo Santos et al. (2011), 60\% da massa da madeira é degradada durante o processo de carbonização para produção de carvão vegetal, consequentemente, quando maior a massa específica do material lenhoso, maior a massa de carvão por volume, o que ocasiona um produto com superior resistência mecânica.

\section{Densidade relativa aparente e Teor de umidade do carvão}

Nos testes de densidade relativa aparente do carvão se observou que a espécie Mumuré apresentou a maior densidade aparente equivalente à 0,3173 $\pm 0,0116 \mathrm{~g} \mathrm{~cm}^{-3}$, diferindo estatisticamente das demais espécies avaliadas. Por outro lado, o Envirão foi a espécie que apresentou o menor valor médio, corresponde a $0,2654 \pm 0,0407 \mathrm{~g} \mathrm{~cm}^{-3}$, não apresentando diferença significativa em relação à Sumaúma (Tabela 5).

\section{Tabela 5 - Estatística descritiva da densidade relativa aparente e do teor de umidade do carvão de resíduos de serraria de três espécies florestais, exploradas no município de Paragominas, Pará.}

Table 5 - Descriptive statistics of apparent relative density and moisture content of charcoal from sawmill residues of three forest species exploited, in the municipality of Paragominas, Pará state.

\begin{tabular}{lcccc}
\hline \multicolumn{1}{c}{ Tratamento } & $\begin{array}{c}\text { Densidade aparente }\left(\mathbf{g} / \mathbf{c m}^{3}\right) \\
\text { Média } \pm \text { Desvio padrão }\end{array}$ & $\begin{array}{c}\text { Coeficiente de } \\
\text { Variação }(\mathbf{C V}) \%\end{array}$ & $\begin{array}{c}\text { Teor de umidade do } \\
\text { carvão }(\%) \\
\text { Média } \pm \text { Desvio padrão }\end{array}$ & $\begin{array}{c}\text { Coeficiente de } \\
\text { Variação }(\mathbf{C V}) \%\end{array}$ \\
\hline $\begin{array}{l}\text { Ceiba pentandra } \\
\text { (L.) Gaertn. }\end{array}$ & $0,2680 \pm 0,0232 \mathrm{~b}$ & 8,65 & $6,91 \pm 0,40 \mathrm{a}$ & 5,83 \\
$\begin{array}{l}\text { Guatteria sp. } \\
\text { Brosimum sp. }\end{array}$ & $0,2654 \pm 0,0407 \mathrm{~b}$ & 15,32 & $6,87 \pm 0,71 \mathrm{a}$ & 10,39 \\
\hline
\end{tabular}

Letras diferentes referem-se a tratamentos estatisticamente diferentes entre si, segundo o teste de Tukey a $95 \%$ de confiabilidade.

Azevedo et al. (2000), estudando a qualidade da madeira de Sumaúma em ecossistema de terra firme, encontraram a densidade relativa aparente do carvão desta espécie dentro do intervalo de $0,254-0,336 \mathrm{~g} / \mathrm{cm}^{3}$, assim o valor médio encontrado para Sumaúma no presente trabalho está de acordo com o apresentado pelo autor citado. No entanto, valor inferior para esta espécie foi encontrado por Albuquerque (2012), correspondendo a $0,19 \mathrm{~g} / \mathrm{cm}^{3}$.

Em relação à espécie Mumuré (Brosimum sp.), valores superiores foram encontrados por Trugilho et al. (1991), ao estudarem espécies nativas e exóticas da Amazônia, onde a densidade relativa aparente do carvão foi equivalente a $0,404 \mathrm{~g} / \mathrm{cm}^{3}$ para o Amapá (B. parinarioides Ducke) e $0,608 \mathrm{~g} / \mathrm{cm}^{3}$ para Pau-rainha (B. rubescens Taub.), ambas espécies do gênero Brosimum.

Foi observado nesse estudo que o carvão de Mumuré foi o mais pesado quando comparado aos carvões de Sumaúma e Envirão. Assim, com base nestes resultados, a espécie Mumuré é a mais indicada para a siderurgia. Logo, pode-se dizer que madeira densa gera carvão também denso. Essa tendência também foi observada por Numazawa (1986), o qual estudou resíduos de três espécies de densidade diferente da região de Curuá-Una/Pará e por Pastore, Okino e Pastore Junior (1989) ao estudarem 20 espécies da região amazônica. Para Santos et al. (2011), carvão com maior densidade, geralmente, é originado de madeira de alta densidade. Esse fato, de modo geral, tende a aumentar a resistência mecânica do carvão, característica importante, especialmente, quando o uso do produto for para fins siderúrgicos.

Sobre o teor de umidade do carvão, a espécie que apresentou o maior valor médio, em 
porcentagem $(7,40 \% \pm 0,29)$ foi o Mumuré, e a espécie que apresentou o menor teor de umidade $(6,87 \% \pm 0,71)$ foi o Envirão (Tabela 5). No entanto, não houve diferença significativa entre as espécies para o teor de umidade do carvão. De acordo com Gomes (2006), entre as características ideais para o carvão siderúrgico tem-se o teor de umidade $\leq 8 \%$.

Para Rosillo-Calle, Bajay e Rothman (2005), o teor de umidade do carvão apresenta-se adequado ao uso energético para a queima, quando sua umidade é inferior a $12 \%$, pois valores superiores a esse reduzem significativamente o valor do calor de combustão, da temperatura da câmara de queima e da temperatura dos gases de escape. Assim, pode-se dizer que todas as espécies avaliadas neste estudo apresentam valores médios de teores de umidade com grande potencialidade para uso.

Em trabalho realizado por Brand et al. (2013), ao estudar Miconia cinnamomifolia (De Candolle) Naudin, o teor de umidade médio do carvão foi de 5,5\%, valor próximo ao obtido por Rosa et al. (2012) para amostras de carvão vegetal de várias origens que variaram entre 4,17; 4,25 e 5,57\%. É importante dizer que a umidade do carvão vegetal é um parâmetro importante, uma vez que pode refletir no rendimento dos processos nos quais o mesmo será empregado (SCHONINGER; ZINELLI, 2012; FERREIRA et al., 2013). Além disso, vale ressaltar que o teor de umidade apresenta uma relação inversa com o poder calorífico, além de prejudicar o armazenamento, uma vez que pode ocasionar a proliferação de fungos e a degradação do material (VALE et al., 2011). A densidade básica da madeira e a densidade relativa aparente do carvão apresentaram correlação positiva para todas as espécies estudadas. Ceiba pentandra (L.) Gaertn. (correlação de Pearson = 0,350), Guatteria sp. (correlação de Pearson =0,747) e Brosimum sp. (correlação de Pearson = 0,712) (Figura 3). Resultados de correlação entre estas variáveis também foram encontrados por Silva et al. (2007) e Santos et al. (2011).

Figura 3 - Correlação entre a densidade básica da madeira e a densidade relativa aparente do carvão de resíduos de serraria de Ceiba pentandra (L.) Gaertn., Guatteria sp. e Brosimum sp., Paragominas, Pará.

Figure 3 - Correlation between the basic density of wood and apparent relative density of charcoal from sawmill residues of Ceiba pentandra (L.) Gaertn., Guatteria sp. e Brosimum sp.,

Paragominas, Pará state.

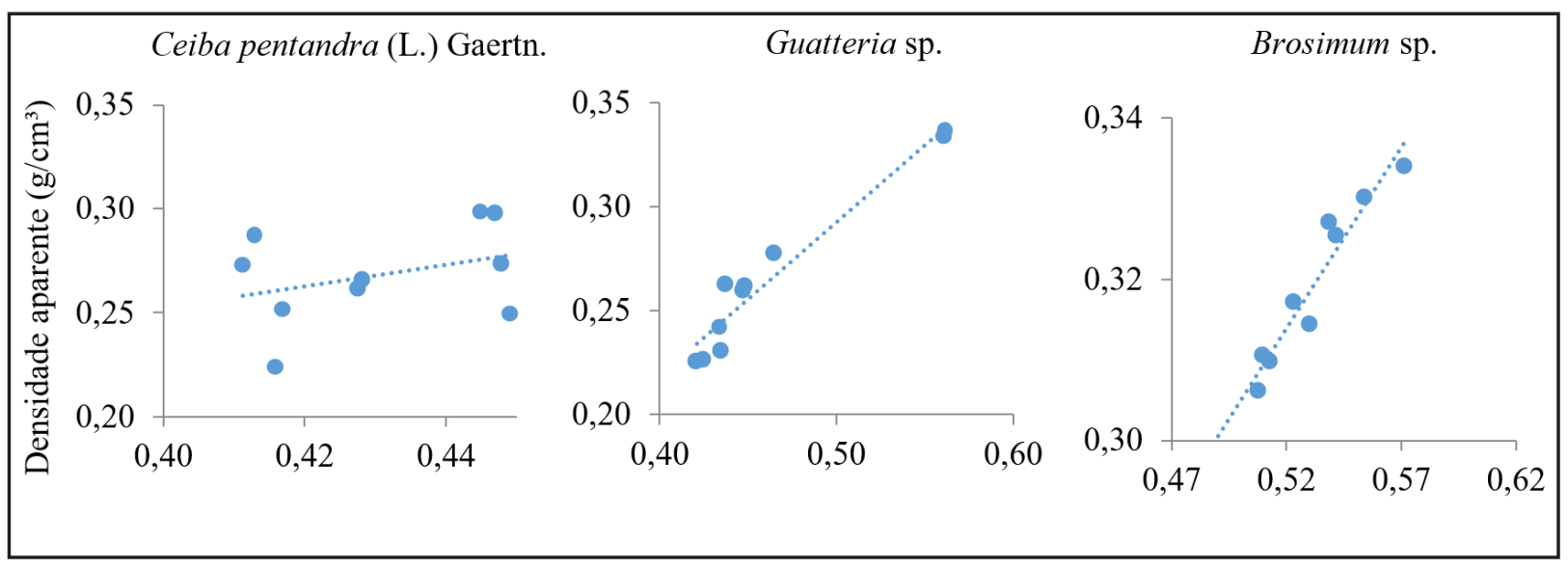

Fonte: Autores (2019)

Alguns autores também observaram a existência da relação direta e positiva entre a densidade básica da madeira e a densidade relativa aparente do carvão, ressaltando que a densidade é uma característica fundamental no carvão vegetal, pois quanto mais denso, maior é a quantidade de energia 
por unidade de volume, além de caracterizar também um produto menos friável (PASTORE; OKINO; PASTORE JUNIOR, 1989; VALE et al., 2001).

Doat e Petroff (1975) observaram uma série de correlações específicas para madeiras de florestas naturais tropicais. Segundo estes autores, uma forte correlação foi encontrada entre a densidade da madeira e a densidade do carvão, o que os levou a afirmarem que para a produção de carvão destinada à siderurgia deve-se de preferência escolher madeiras densas e compactas. No entanto, vale ressaltar que se tratando de madeiras da Amazônia, dada a diversidade de espécies arbóreas existentes, pode-se esperar variações no que diz respeito às propriedades químicas e físicas de suas madeiras.

\section{Composição química imediata}

Os resultados obtidos para a análise de variância das propriedades químicas do carvão são apresentados na Tabela 6. As análises estatísticas indicaram que o fator tratamento, neste caso as espécies, não apresentou efeito significativo em todos os parâmetros avaliados, evidenciando a interdependência do fator espécie sobre os parâmetros.

\section{Tabela 6 - Valores do teste F da Análise de Variância dos dados coletados do carvão proveniente de resíduos de serraria de três espécies florestais, exploradas no município de Paragominas, Pará.}

Table 6 - Values of F test of the Variance Analysis of the collected data of charcoal coming from sawmill residues of three forest species exploited, in the municipality of Paragominas, Pará state.

\begin{tabular}{lcccc}
\hline $\begin{array}{l}\text { Causa de } \\
\text { Variação }\end{array}$ & GL & Teor de cinzas & $\begin{array}{c}\text { Teor de materiais } \\
\text { voláteis }\end{array}$ & $\begin{array}{c}\text { Teor de } \\
\text { carbono fixo }\end{array}$ \\
\hline Espécies & 2 & 0,893 & 0,272 & 0,309 \\
Resíduos & 12 & - & - & - \\
Total & 14 & - & - & - \\
\hline
\end{tabular}

Em que: GL = Grau de liberdade

Tratando-se do teor de cinzas, as médias podem ser observadas na Tabela 7. Verifica-se que os valores apresentados estão dentro do limite dos carvões de madeiras tropicais encontrados por outros pesquisadores tais como Numazawa (1986), que encontraram valores variando de 0,43 a $1,76 \%$, respectivamente.

De maneira geral, a madeira de Envirão foi a espécie que apresentou o maior teor de cinzas e o menor teor de materiais voláteis, indicando que o teor de cinzas é inversamente proporcional ao teor de voláteis, de acordo com as características em que o presente estudo foi realizado. No entanto, verifica-se o contrário em estudo realizado por Brand et al. (2013), em que os autores afirmam que o aumento do teor de cinzas está relacionado ao aumento do teor de voláteis.

O teor de cinzas foi considerado baixo, considerando que o teor apresentou valor inferior a 5\%, o que, conforme Brand et al. (2013), é positivo para o uso energético da madeira, tanto na forma de lenha como para a produção de carvão vegetal. Gomes (2006) afirma que entre as características ideais para o carvão siderúrgico, deve-se citar o teor de cinzas, podendo variar de 1 a $2 \%$. Nestas condições, pode-se afirmar que os teores de cinzas encontrados para todas as espécies avaliadas no presente trabalho estão de acordo com o recomendado pela literatura.

Tratando-se do teor de materiais voláteis, as médias encontradas variaram de 31,65 a 33,77\% (Tabela 7). De acordo com a Cetec (1982), recomenda-se que os teores de matérias voláteis estejam dentro de uma faixa de $19,6 \%$ a $23,5 \%$. No entanto, para atingir estes percentuais recomendados, a carbonização deve ser realizada em temperaturas ainda mais altas que $500^{\circ} \mathrm{C}$ 
(SCREMIN, 2012), a mesma aplicada no presente trabalho.

\section{Tabela 7 - Estatística descritiva do teor de cinzas, materiais voláteis e carbono fixo, provenientes do carvão dos resíduos de serraria de três espécies florestais, exploradas no município de Paragominas, Pará.}

Table 7 - Descriptive statistics of ash content, volatiles levels, and fixed carbon originated from sawmill residues from three forest species, exploited in the municipality of Paragominas, Pará state.

\begin{tabular}{lccc}
\hline \multicolumn{1}{c}{ Tratamento } & Teor de cinzas $(\mathbf{\%})$ & $\begin{array}{c}\text { Teor de materiais } \\
\text { voláteis }(\%)\end{array}$ & $\begin{array}{c}\text { Teor de carbono fixo } \\
(\%)\end{array}$ \\
\hline Ceiba pentandra (L.) Gaertn. & $0,97 \pm 0,68$ & $33,77 \pm 3,72$ & $65,27 \pm 3,24$ \\
Guatteria sp. & $1,03 \pm 0,64$ & $31,65 \pm 4,66$ & $67,32 \pm 4,78$ \\
Brosimum sp. & $0,60 \pm 0,14$ & $32,28 \pm 5,47$ & $67,12 \pm 5,41$ \\
\hline
\end{tabular}

Essa variação é resultante de fatores como a temperatura da carbonização, taxa de aquecimento e composição química da madeira. Trugilho et al. (2005) estudando híbridos naturais de Eucalyptus em Vazante/MG encontraram uma taxa para materiais voláteis que variou entre 30,04-32,08\%, bem próximos ao encontrado neste estudo, assim como Brand et al. (2013), ao estudarem Miconia cinnamomifolia (De Candolle) Naudin, obtendo valores entre 29,07-32,78\%. No entanto, Rosa et al. (2012), avaliando amostras de carvão de três locais distintos (Alegre, Jerônimo Monteiro e Cachoeira do Itapemirim, todos localizados no Espírito Santo) encontraram valores médios inferiores para o teor de voláteis, variando de 15,65\% a 23,64\%.

Valores elevados foram encontrados por Scremin (2012) analisando o teor de materiais voláteis do carvão vegetal de Eucalyptus dunnii Maiden em diferentes médias das temperaturas, em que a menor temperatura $\left(300^{\circ} \mathrm{C}\right)$ apresentou um teor equivalente a $80,15 \%$ e a maior temperatura $\left(500^{\circ} \mathrm{C}\right)$, um teor de $34,34 \%$. O autor afirma que pela análise estatística, percebe-se que há uma tendência da diminuição do teor de materiais voláteis à medida que há o aumento da temperatura. Isso pode explicar o que ocorreu no presente estudo, visto que quando a temperatura de carbonização foi a mesma, neste caso $500^{\circ} \mathrm{C}$, Scremin (2012) obteve um valor equivalente a $34,34 \%$ para o teor de voláteis, resultado próximo ao encontrado.

Segundo a literatura, combustíveis com altos teores de carbono fixo e baixos teores de materiais voláteis tendem a se queimar mais lentamente, ou seja, eles poderão requerer longo tempo de residência na fornalha para queima total, quando comparados com combustíveis que possuam baixo índice de carbono fixo (BRAND, 2010). Logo, madeiras com teores elevados de voláteis carbonizam mais rapidamente, pois, os voláteis quando submetidos a altas temperaturas evaporam-se e ao entrar em contato com o oxigênio do ar, ocorrendo combustão mais rápida.

Sobre o teor de carbono fixo, as médias encontradas variaram de 65,27 a 67,32\% (Tabela 7). Resultados próximos foram observados por Costa et al. (2014) estudando cinco espécies de ocorrência no Cerrado, assim como Assis et al. (2012) avaliando o clone de um híbrido de Eucalyptus em diferentes idades e locais. O Selo Premium destaca que o teor de carbono fixo deve ser superior a 75\% (SÃO PAULO, 2003).

Para Scremin (2012), quanto maior for a temperatura final durante o processo de carbonização, maior será a porcentagem de carbono fixo e menor o teor de voláteis. Este autor, analisando o teor de carbono fixo do carvão vegetal de Eucalyptus dunnii Maiden em diferentes médias das temperaturas, observou que, a uma temperatura de $300^{\circ} \mathrm{C}$, o carvão vegetal apresentou $15,23 \%$ de carbono fixo, e que quando a temperatura subia até $500^{\circ} \mathrm{C}$, o teor de carbono fixo correspondia a $53,60 \%$.

Trugilho et al. (2005) estudando híbridos naturais de Eucalyptus em Vazante/MG 
encontraram uma taxa para carbono fixo que variou entre $67,71-69,71 \%$, resultados próximos ao encontrado neste estudo. Entretanto, os teores de carbono fixo observados ficaram abaixo dos encontrados por Pereira, Schaitza e Baggio (2000) que foi de 81,10\% para Grevillea robusta e de 81,85 \%, para Eucalyptus benthamii, de acordo com Lima et al. (2007), realizando a carbonização em forno elétrico (mufla) à temperatura máxima de $500^{\circ} \mathrm{C}$.

\section{Conclusão}

Houve influência do fator espécie sobre as propriedades de densidade básica e teor de umidade da madeira, rendimento gravimétrico e densidade aparente do carvão. Com exceção do teor de umidade do carvão e composição química imediata (teor de cinzas, materiais voláteis e carbono fixo).

A correlação entre a densidade básica da madeira e o rendimento gravimétrico foi positiva para as espécies Ceiba pentandra (L.) Gaertn e Guatteria sp., e negativa para a espécie Brosimum sp. Enquanto que, a correlação entre a densidade básica da madeira e a densidade aparente do carvão foi positiva para todas as espécies avaliadas.

A relação positiva entre os valores de densidade da madeira e do carvão intensifica a importância da separação de resíduos por espécie. Assim como, a sua escolha para produção de carvão, permitindo prever as características desse produto mediante a avaliação da densidade de sua madeira, além de proporcionar o direcionamento das empresas do ramo em sua produção conforme a necessidade do consumidor.

Brosimum sp. foi a espécie que apresentou a densidade mais elevada, garantindo a produção de carvão mais denso. Além de apresentar um menor teor de cinzas quando comparado às outras espécies, assim como um teor de materiais voláteis e teor de carbono fixo dentro do limite recomendado pela literatura, quando se considera a temperatura utilizada para carbonização.

De maneira geral, todas as espécies apresentam propriedades adequadas para a produção de carvão vegetal.

\section{Referências}

ASSOCIAÇÃO BRASILEIRA DE NORMAS TÉCNICAS. NBR 8112/1986: Carvão vegetal: análise imediata. Rio de Janeiro, 1986. 5 p.

ASSOCIAÇÃO BRASILEIRA DE NORMAS TÉCNICAS. NBR 7190/1997: Projeto de estruturas de madeira. Rio de Janeiro, 1997. 107 p.

ASSOCIAÇÃO BRASILEIRA DE PRODUTORES DE FLORESTAS PLANTADAS. Anuário estatístico da ABRAF 2011: ano base 2010. Brasília, 2011. 130 p.

ALBUQUERQUE, A. R. Anatomia comparada do lenho e do carvão aplicada na identificação de 75 espécies da floresta Amazônica, no Estado do Pará, Brasil. 2012. Dissertação (Mestrado em Ciências) - Universidade de São Paulo, Escola Superior de Agricultura “Luiz de Queiroz”, São Paulo, 2012.

ASSOCIAÇÃO MINEIRA DE SILVICULTURA. Números do setor. Belo Horizonte, 2009. Disponível em: www.silviminas.com.br. Acesso em: 22 maio 2016.

ARAÚJO, H. J. B. de. Relações funcionais entre propriedades físicas e mecânicas de madeiras tropicais brasileiras. Floresta, Curitiba, v. 37, n. 3, p. 399-416, 2007.

ARRUDA, T. P. M. de et al. Avaliação de duas rotinas de carbonização em fornos retangulares. Revista Árvore, Viçosa, MG, v. 35, n. 4, p. 949-955, 2011.

ASSIS, M. R. de et al. Qualidade e rendimento do carvão vegetal de um clone híbrido de Eucalyptus

Ci. Fl., Santa Maria, v. 29, n. 3, p. 1436-1451, jul./set. 2019 
grandis x Eucalyptus urophylla. Pesquisa Florestal Brasileira, Colombo, v. 2, n. 71, p. 291-302, 2012.

AZEVEDO, C. P. de et al. Qualidade da madeira de sumaúma Ceiba pentandra plantada em ecossistemas de várzea e terra firme e em diferentes sistemas de plantios. In: CONGRESSO BRASILEIRO DE SISTEMAS AGROFLORESTAIS, 2000, Manaus. Anais [...] Manaus: EMBRAPA Amazônia Ocidental, 20000. p. 264-266.

BRAND, M. A. Energia de Biomassa Florestal. 1. ed. Rio de Janeiro: Interciência, 2010. 114 p.

BRAND, M. A. et al. Análise da qualidade da madeira e do carvão vegetal produzido a partir da espécie Miconia cinnamomifolia (De Candolle) Naudin (Jacatirão-açu) na agricultura familiar, em Biguaçu, Santa Catarina. Scientia Forestalis, Piracicaba, v. 41, n. 99, p. 401-410, 2013.

BRASIL. Ministério Público Federal. Termo de Compromisso e Ajuste de Conduta. Belém: Procuradoria da República no Pará, 2012.

BRITO, J. O. Reflexões sobre a qualidade do carvão vegetal para uso siderúrgico. Piracicaba: IPEF, 1993. 6 p. (Circular Técnica, 181).

CHUDNOFF, M. Tropical timber of the world. [S. l.]: Forest Products Laboratory, Forest Service, 1980. $831 \mathrm{p}$.

CITY BRASIL. Paragominas. Dados gerais. Clima/Temperatura. [2016]. Disponível em: www. citybrazil.com.br. Acesso em: 22 maio 2016.

COSTA, T. G. et al. Qualidade da madeira de cinco espécies de ocorrência no cerrado para produção de carvão vegetal. Cerne, Lavras, MG, v. 20, 2014.

DANCEY, C.; REIDY, J. Estatística sem matemática para psicologia: usando SPSS para Windows. Porto Alegre: Artmed, 2006.

DOAT, J.; PETROFF, G. La carbonization des bois tropicaux. Bois et Forêst des Tropiques, Nogent-sur-Marne, v. 159, p. 55-72, 1975.

FERREIRA, H. R. et al. Análise da qualidade do carvão vegetal proveniente da região Sul do Brasil. Revista Acadêmica, Ciências Agrárias e Ambientais, Curitiba, v. 11, supl 1, p. S27-S33, 2013.

FOELKEL, C. E. B.; BRASIL, M. A. M.; BARRICHELO, L. E. G. Métodos para determinação da densidade básica de cavacos para coníferas e folhosas. IPEF, Piracicaba, n. 2/3, p. 65-74, 1971.

FUNDAÇÃO CENTRO TECNOLÓGICO DE MINAS GERAIS. Produção e utilização de carvão vegetal. Belo Horizonte, 1982. 393 p. (Séries Técnicas CETEC).

GOMES, M. T. M. Potencialidades de inserção do carvão vegetal em bolsas de mercadoria. 2006. Dissertação (Mestrado em Ciências Florestais) - Universidade Federal de Viçosa, Viçosa, MG, 2006.

GONÇALEZ, J. C. et al. Relações entre dimensões de fibras e de densidade da madeira ao longo do tronco de Eucalyptus urograndis. Scientia Forestalis, Piracicaba, v. 42, n. 101, p. 81-89, 2014.

JARA, E. R. P. O Poder calorífico de algumas madeiras que ocorrem no Brasil. São Paulo: Instituto de Pesquisas Tecnológicas, 1989.

LIMA, E. A. de; ABDALA, E. M.; WENZEL, A. A. Influência da umidade no poder calorífico superior da madeira. Colombo: EMBRAPA Florestas, 2008. 3 p. (Comunicado Técnico, 220).

LIMA, E. A. de et al. Caracterização individual de árvores de Eucalyptus benthamii para uso energético. Boletim de Pesquisa e Desenvolvimento da Embrapa, Colombo, n. 35, p. 1-26, 2007.

LOUREIRO, A. A. et al. Essências madeireiras da Amazônia. Manaus: CNPq; INPA, 2000. v. 4. 
MARTINS, M. E. G. Coeficiente de correlação amostral. Revista de Ciência Elementar, Porto, v. 2, n. 02, 2014.

MEDEIROS NETO, P. N. de et al. Características físico-químicas e energéticas de duas espécies de ocorrência no Semiárido Brasileiro. Ciência Florestal, Santa Maria, v. 22, n. 3, p. 579-588, 2012.

NOGUEIRA, E. M. et al. Wood density in forests of Brazil's 'arc of deforestation': implications for biomass and flux of carbon from land-use change in Amazonia. Forest Ecology and Management, Amsterdam, v. 248, p. 119-135, 2007.

NUMAZAWA, S. Aproveitamento de resíduos de exploração florestal em Curuá-Una/Pa, para produção de carvão vegetal. 1986. Dissertação (Mestrado em Ciências) - Universidade Federal do Paraná, Curitiba, 1986.

OLIVEIRA, A. C. et al. Parâmetros de qualidade da madeira e do carvão vegetal de Eucalyptus pellita F. Muell. Scientia Forestalis, Piracicaba, v. 38, n. 87, p. 431-439, 2010.

PASTORE, T. C. M.; OKINO, E. Y. A.; PASTORE JUNIOR, F. Carbonização de Madeiras da Amazônia. Parte 1: Floresta Nacional do Tapajós. Brasília: IBAMA, Laboratório de Produtos Florestais, 1989. 12 p. (Série Técnica, 12).

PEREIRA, J. C. D.; SCHAITZA, E. G.; BAGGIO, A. J. Propriedades físicas e químicas e rendimentos da destilação seca da madeira de Grevillea robusta. Colombo: EMBRAPA Florestas, 2000. (Circular Técnica, 40).

ROSA, R. A. et al. Qualidade do carvão vegetal para o consumo doméstico. Journal of Biotechnology and Biodiversity, Gurupí, v. 3, n. 2, p. 41-48, 2012.

ROSILLO-CALLE, F.; BAJAY, S. V.; ROTHMAN, H. Uso da biomassa para produção de energia na indústria brasileira. Campinas: UNICAMP, 2005.

SANTOS, R. C. dos et al. Correlações entre os parâmetros de qualidade da madeira e do carvão vegetal de clones de eucalipto. Scientia Forestalis, Piracicaba, v. 39, n. 90, p. 221-230, 2011.

SÃO PAULO (Estado). Secretaria de Agricultura e Abastecimento de São Paulo. Resolução n ${ }^{\circ} \mathbf{1 0}$ SAA, de 11 de julho de 2003. São Paulo, 2003.

SCHONINGER, E. C.; ZINELLI, M. R. Análise qualitativa dos carvões de Apuleia leiocarpa e Hymenaea courbaril produzidos numa carvoaria de Matupá, no Estado de Mato Grosso. Revista de Ciências Agro-Ambientais, Cáceres, v. 10, n. 2, p. 135-140, 2012.

SCREMIN, A. L. T. Estudo energético e físico-químico do carvão vegetal de Eucalyptus dunnii Maiden. 2012. Dissertação (Mestrado em Biocombustíveis) - Universidade Estadual do CentroOeste, Guarapuava, 2012.

SILVA, M. G. da et al. Carvão de resíduos de indústria madeireira de três espécies florestais exploradas no município de Paragominas, PA. Acta Amazonica, Manaus, v. 37, n. 1, p. 61-70, 2007.

TRUGILHO, P. F. et al. Caracterização de espécies nativas e exóticas amazônicas e do carvão vegetal. Revista Árvore, Viçosa, MG, v. 15, n. 2, p. 144-151, 1991.

TRUGILHO, P. F. et al. Rendimentos e características do carvão vegetal em função da posição radial de amostragem em clones de Eucalyptus. Cerne, Lavras, MG, v. 11, n. 2, p. 178-186, 2005.

VALE, A. T. do et al. Potencial energético da biomassa e carvão vegetal do epicarpo e da torta de Pinhão manso (Jatropha curcas). Cerne, Lavras, MG, v. 17, n. 2, p. 267-273, 2011.

VALE, A. T. do et al. Relações entre a densidade básica da madeira, o rendimento e a qualidade do carvão vegetal de espécies do cerrado. Revista Árvore, Viçosa, MG, v. 25, n. 89, p. 89-95, 2001. 
VALE, A. T. do.; DIAS, I. S.; SANTANA, M. A. E. Relações entre propriedades químicas, físicas e energéticas da madeira de cinco espécies de cerrado. Ciência Florestal, Santa Maria, v. 20, n. 1, p. 137-145, 2010.

VALE, A. T. do; NOGUEIRA, M. Carbonização de madeiras do Cerrado e análise do carvão vegetal. Revista Árvore, Viçosa, MG, v. 25, n. 2, p. 271-276, 2001.

VALE, A. T. do; SARMENTO, T. R.; ALMEIDA, A. N. Caracterização e uso de madeiras de galhos de árvores provenientes da arborização de Brasília - DF. Ciência Florestal, Santa Maria, v. 15, n. 4, p. 411-420, 2005.

WIECHETECK, M. Aproveitamento de resíduos e subprodutos florestais, alternativas tecnológicas e propostas de políticas ao uso de resíduos florestais para fins energéticos. Curitiba: Ministério do Meio Ambiente. Secretaria de Mudanças Climáticas e Qualidade Ambiental, 2009. 40 p. 